\title{
Applications and Technology of Electronic Nose for Clinical Diagnosis
}

\author{
Simeng Chen, Yuchao Wang, Seokheun Choi ${ }^{*}$ \\ Department of Electrical \& Computer Engineering, State University of New York at Binghamton, Binghamton, USA \\ Email: sechoi@binghamton.edu
}

Received January 28, 2013; revised March 14, 2013; accepted March 22, 2013

Copyright (C) 2013 Simeng Chen et al. This is an open access article distributed under the Creative Commons Attribution License, which permits unrestricted use, distribution, and reproduction in any medium, provided the original work is properly cited.

\begin{abstract}
Rapid advances in sensor technologies have facilitated the development of high-performance electronic noses that can detect and discriminate volatile compounds in situ. The research and development of electronic noses has resulted in a new qualitative and semi-quantitative detection approach in the field of clinical diagnostics. Electronic noses have a clear potential to be a non-invasive, simple and rapid but above all accurate early diagnostic screening tool. This review collates existing knowledge of recent advances in electronic nose technologies and applications.
\end{abstract}

Keywords: Electronic Nose; Biosensor; Clinical Diagnosis

\section{Introduction}

Due to an increase in awareness that the early detection of diseases greatly increases the chances for successful treatment, there is an urge in demand for inexpensive, non-invasive, simple, and fast early qualitative diagnosis of diseases. Using odors to detect diseases can be traced back to ancient times, originating with Hippocrates around 400 B.C., and is directly related to traditional medicine in different cultures [1].The selective detection of various volatile compounds in odors sampled from the human body is of great significance to early clinical diagnosis. Many methodologies have been applied to investtigate the odor feature of samples, and human assessment has been the main tool of diagnosis for many years. However, this evaluation has its deficiencies, such as subjecttivity, variability, time consumption, low reproducibility, fatigue, and infections. Recently, an objective instrument like gas chromatography coupled with mass spectrometry has become one of the most widely used analytical detectors for clinical diagnosis [2]. Nevertheless, these analytical instruments are large, expensive and require trained operators, which place significant limitations on their applications and potential markets. Therefore, a new instrumental methodology of mimicking the human olfactory perceptions to odor profiles can revolutionize clinical diagnostics because of its ability to be a noninvasive, simple, rapid and accurate early diagnostic tool.

${ }^{*}$ Corresponding author.
Along with the significant developments in biosensors, electronic noses have been developed for detecting volatile compounds from the human body for clinical diagnosis, such as rapid detection of tuberculosis (TB), Helicobacter pylori (HP) and urinary tract infections (UTI).

This review aims to describe the use of electronic noses in clinical diagnosis. The main features and the working principles of modern electronic noses are introduced. The current electronic nose technology and the most relevant contributions in disease diagnoses are presented afterwards. Finally, some interesting remarks concerning the challenges and future trends of electronic noses in medical application are mentioned.

\section{Components and Techniques of an E-Nose in Clinical Diagnosis}

An electronic nose is first defined as a device which comprises of an array of chemical sensors with different selectivity, a signal-preprocessing unit and a pattern recognition system [3].The interaction between volatile organic compounds (VOC) with an array of sensors generates a characteristic fingerprint which can be recognized by comparing it with previously recorded patterns in the recognition system. Electronic noses can be used for detecting bacterial pathogens, either in vitro or in vivo, or as a potential tool for the identification of patients with diseases, such as lung cancer, chronic obstructive pulmonary disease (COPD) and asthma [4]. In a broader sense, an electronic nose device is composed of three 
systems: 1) a sample delivery system, 2) a detection system and 3) a data computing system [5].

\subsection{Sample Delivery System}

The sample delivery system introduces odors to be analyzed into the detection system. It includes a pretreatment step whose goal is to enrich, clean up and enhance the signal. Although this step tends to be slow and laborintensive, it improves the quality of the analysis by adopting an appropriate sampling technique. Current main techniques to introduce the volatile compounds extracted from samples into the electronic nose detection system are described thereafter.

\subsubsection{Static Headspace Extraction (SHS)}

Static headspace extraction (SHS) is one of the most common techniques for quantitative and qualitative analysis of volatile compounds from a variety of matrices. In the SHS technique, a sample is placed in a hermetically sealed vial and then volatile components can be extracted from the sample once equilibrium has been established between the matrix and the gaseous phase. The form of matrix of the sample, vial volume and temperature are the main factors to optimize the extraction for efficiency, sensitivity, quantitation and reproducibility. Bernabei et al. has adopted SHS to extract volatile compounds from the headspace of urine samples for diagnosing urinary tract cancers experiment [6].

\subsubsection{Dynamic Headspace Extraction (DHS)}

Dynamic headspace extraction (DHS) or purge and trap (P\&T) relies on the volatility of analytes to achieve extraction from the matrix like SHS technique. However, VOC are removed from the sample continuously by a flowing gas before equilibrium is achieved between the gaseous phase and matrix. In the purge and trap technique, samples are placed in a purged vessel and the volatile components are purged by a stream of inert gas and trapped into an adsorbent. The trap is subsequently heated to desorb VOC molecules into a detection system which increases sensitivity for analysis. Kanoh et al. undertook a study of diagnosing interstitial lung diseases using trap and purge to concentrate ethane from exhaled breath samples. Activated coconut charcoal surrounded by dry ice is used as adsorbent to trap the sampled gas and then heated to drive off the absorbed ethane. The desorbed gas was transferred to an airtight syringe for analysis [7].

\subsubsection{Solid-Phase Microextraction (SPME)}

Solid-phase microextraction (SPME) involves the use of a fiber coated with sorptive material in the headspace of the sample to extract volatile analytes from a sample ma- trix onto the fiber. After extraction has ideally reached equilibrium, the fiber is heated to desorb the solutes into the detection system. Success relies on choosing an appropriate coating for volatile analytes, extraction time, sample volume, heating temperature, and modification of the sample matrix. For multianalyte extraction, the use of several diverse SPME fiber coatings can be taken into consideration. Dixon et al. employed SPME to facilitate the isolation and analysis of VOCs from human feces for diagnosing human health conditions. They indicated that multifarious nature of metabolites present in human feces dictates the use of different SPME fiber coatings. Eight different SPME fibers are utilized as a set of fibers appropriate for human fecal VOC metabolomics and obtained an evaluation of $90 \%$ isolation of the total metabolites [8].

There are a variety of techniques available for the extraction of VOCs from various matrices. The choice of sampling headspace technique used as the sample delivery system depends on the type of sample matrix, information required (quantitative or qualitative), sensitivity required, the need for automation and budget. SHS is the most widely used extraction method due to its minimal sample preparation, simplicity, rapidity, use of little or no solvent, and inexpensive characteristic. However, SHS has a low sensitivity as analytes are not pre-concentrated. Introducing a pre-concentration step can improve sensitivity, at the cost of increasing the time of analysis. In addition, incomplete desorption of VOCs, introductions of impurities, decomposition of analytes and irreversible adsorption might occur during the pre-concentration step. For instance, silica gel and Tenax are commonly used sorbents for trapping VOCs. Tenax is a porous polymer resin which has a low affinity for water. However, highly volatile compounds and polar volatile compounds are poorly retained on Tenax. It might decompose when heated to temperature above $200^{\circ} \mathrm{C}$. Silica gel is a stronger sorbent than Tenax and its hydrophilic characteristic makes it an excellent material for trapping polar compounds but it also retains water.

\subsection{Detection System}

Technology in detection systems has developed signifycantly along with advances in different sensor platforms and complex microarray devices. Since the first sensor array was developed using Metal Oxide Semiconductor (MOS), various advanced devices based on nanotechnology have been developed including metal oxide semiconducting field effect transistors (MOSFET), conducting polymer sensors (CP), optical sensors, quartz crystal microbalance sensors (QCM), and surface acoustic sensors (SAW) [9-13]. 


\subsubsection{Metal Oxide Semiconductor (MOS) Sensor}

MOS sensors are one of the most commonly utilized sensor systems as they possess a broad range of electronic, chemical, optical and physical properties that are often stable to vary with the composition of surrounding gas atmosphere [14]. The oxide materials in MOS sensors contain chemically adsorbed oxygen species, which can interact with gaseous molecules on the metal oxide surface thus altering the conductivity of the oxide [15]. The change in resistance depends on the VOC that interacts with the adsorbed oxygen on the semiconductor, the metal oxide grain size and the temperature at which the sensing takes place [16]. MOS sensors have the advantage of being inexpensive, robust, long lasting and rapidly responsive; nevertheless, they require high-temperature material processing, generally functioning at $300-500^{\circ} \mathrm{C}$, to allow rapid and reversible reactions at the sensor surface and avoid formation of a layer of chemisorbed water that would inhibit the reaction with VOCs [17-20]. These results in large power consumption especially in traditional MOS sensors configured as single crystals, thin/thick films and ceramics [21-23].

\subsubsection{Metal-Oxide-Semiconductor Field-Effect Transistor (MOSFET)}

MOSFET odor sensing devices works on the principle that VOCs interact with the gate material, usually a catalytic metal, leading to gas diffusion through the gate and thus changing the threshold voltage of the device. It has been proven that the shift of the threshold voltage is proportional to the concentration of the analyte. For gas diffusion to occur, a porous gas sensitive gate material is required to facilitate diffusion of gas into the material [24]. Conducting polymers have been widely used as the gate material, such as poly (ethylene-co-vinyl, acetate, poly (styrene-co-butadiene), poly (9-vinylcarbazole) and platinum (Pt), palladium (Pd) and iridium (Ir) can be employed as catalytic metals. MOSFETs can be produced using standard micro-fabrication techniques and operated at much lower temperatures (around $150^{\circ} \mathrm{C}$ ) than MOS sensors. The sensitivity can be optimized by changing the gate material and thickness, porosity of the metal gate, and operation at different temperatures. MOSFET sensors are robust and can be made with IC fabrication processes which minimize batch-to-batch variations. However, MOSFET sensors undergo baseline drift similar to that of the conductivity sensors.

\subsubsection{Conducting Polymer (CP) Sensors}

Conducting polymers are widely used as sensor elements in electronic noses as they provide different reversible physic-chemical properties and high sensitivity to groups of volatile compounds. In these sensors, interaction between polymers and volatile compounds lead to a change in resistance of conducting polymers on a sensor surface. Different polymers respond to diverse vapors with different physiochemical properties and properties of CPs strongly depend on doping level, ion size of the dopant, protonation level and water content. A number of clinical applications of conducting polymers to electronic noses have been performed in several years. Aathithan et al. used a commercial electronic nose consisting of an array of polymer sensors to diagnose bacteriuria by detection of VOCs in urine [23]. Fend et al. used an electronic nose consisting of 14 different polymers to implement early detection of Tuberculosis [25]. In comparison with MOS which operates at high temperature, $\mathrm{CP}$ sensors can quickly respond to VOCs under ambient temperature conditions [26]. However, CPs are easily affected by humidity and sensor drift due to oxidation of the polymer over time [27].

\subsubsection{Optical Sensors}

In optical electronic noses, a light source excites the volatile analyte, producing a signal that can be measured in resulting absorbance, fluorescence, polarization, refractive index, interference, scattering and reflectance [28]. An optical sensor in detection system comprises four basic components: a light source, suitable optics for directing light to and from the sensor, sensing materials or sensor and a photodetector for detecting light signals coming from the sensor. A wide selection of light sources are available for optical sensors, including highly coherent gas and semiconductor diode lasers, broad spectral band incandescent lamps, and narrow-band, solid-state, light-emitting diodes (LEDs) [29-32]. Photodiodes, CCD and CMOS cameras can be employed to detect output signals, but the choice must be made carefully and take into account the specifications required, such as sensitivity, detectivity, noise, spectral response, and response time. Optical sensors can generally be categorized into two types, i.e. intrinsic optical and extrinsic optical sensors. For an intrinsic sensor, gaseous compounds can be detected directly by measuring changes in optical properties on the sensing surface such as absorbance, fluorescence and refractive index at their absorption, emission or resonance wavelengths. Based on this idea, some approaches applied to electronic noses have been developed including waveguides method, surface plasmon resonance, interference or reflection-based method, and scanning light-pulse technique. For an extrinsic sensor, an indicating species is employed to detect the analyte by being attached on an optical substrate. Indicators can be dyes, polymers or other materials that interact with the analyte to produce signal modulation. The colorimetric method is the most commonly used technique using this theory. Over the past two decades, advanced optical sensing in clinical diagnosis applica- 
tions has been developed with the advent of revolutions in detector technology. In a breath analysis study, Wang and Sahay analyzed 14 of the established breath biomarkers, i.e., ethane, ammonia, acetone, nitric oxide and carban dioxide by applying a laser absorption spectroscopic technique [33]. Mitsubayashi et al. conducted research on an optical bio-sniffer for methyl mercaptan in halitosis [34]. Choi et al. used a SPR protein sensor using the Vroman effect for real-time, sensitive and selective detection of proteins. This protein detector can be integrated with microfluidic systems which can provide extremely sensitive and selective analytical capability [35].

\subsubsection{Piezoelectric Sensors}

Piezoelectric sensors rely on the piezoelectric effect, discovered by the Curie brothers in 1880, which states that certain crystals generate an electrical potential proportional to an applied mechanical stress. Inversely, when an electric potential is applied, piezoelectric crystals undergo a mechanical deformation which can in turncreate a mechanical pressure. In these sensors, piezoelectric crystals have a resonant frequency which is highly sensitive to the mass change applied to the crystals [28]. Selective coating sallow specific gaseous compounds to be adsorbed on the crystal, leading to an increase in mass and changing the frequency of oscillation correlated with analyte concentration. Several different forms of piezoelectric sensors exist, including bulk acoustic wave (BAW), surface acoustic wave (SAW), quartz crystal microbalance (QCM), flexural plate wave (FPW) and shear horizontal acoustic plate mode (SHAPM). Many researchers are involved with optimizing the methodology of piezoelectric sensor. Wang et al. used a pair of SAW sensors to detect different VOCs exhaled by lung cancer cells. Breaths odors are collected in inert Tedlar bags and pre-concentrated by a heat desorption system. Polymer film was attached on the surface of SAW sensors to improve the sensitivity of detection. VOCs were continuously absorbed on the polymer coated SAW sensor and the frequency response was detected. The SAW sensors can discriminate breath from lung cancer patients, chronic bronchitis patients and healthy persons for pathology analysis. It was found that the results from the SAW sensors compared favorably with those obtained by GC-MS [36]. An electronic nose based on eight QCM gas sensors was employed to measure urine headspace for an early and non-invasive diagnosis of urinary tract cancers. QCM sensors are coated by sensing layers of metalloporphyrins. It is shown that the electronic nose is able to detect anomalous composition of urine headspace and has $100 \%$ accuracy for classification of patients and healthy people [6].

Table 1 gives an overall summary in advantages, disadvantages, and application fields for the mentioned sensing methods.

\subsection{Data Computing System}

In data computing systems, pattern-recognition techni-

Table 1. A summary of gas sensing methods.

\begin{tabular}{|c|c|c|c|c|c|}
\hline Sensor Type & Principle & Sensitivity & Advantages & Disadvantages & Ref. \\
\hline $\begin{array}{l}\text { Metal Oxide } \\
\text { Semiconductors }\end{array}$ & Conductivity & $5-500 \mathrm{ppm}$ & $\begin{array}{l}\text { Low cost; } \\
\text { Short response time; long-lasting }\end{array}$ & $\begin{array}{l}\text { Relatively low sensitivity; } \\
\text { High energy consumption }\end{array}$ & {$[37,38]$} \\
\hline $\begin{array}{l}\text { Conducting } \\
\text { Polymers }\end{array}$ & Conductivity & 0.1 - 100 ppm & $\begin{array}{c}\text { Short response time } \\
\text { Low cost of fabrication; } \\
\text { portable structure; } \\
\text { Low energy consumption }\end{array}$ & $\begin{array}{l}\text { Long-time instability; } \\
\text { Irreversibility; } \\
\text { Poor selectivity }\end{array}$ & [39-41] \\
\hline Optical & $\begin{array}{c}\text { Fluorescence; } \\
\text { Chemoluminescence }\end{array}$ & $\begin{array}{l}\text { Low parts per } \\
\text { billion } \\
\text { (ppb) }\end{array}$ & $\begin{array}{c}\text { High sensitivity; } \\
\text { Long lifetime; } \\
\text { Insensitive to environment change }\end{array}$ & $\begin{array}{c}\text { Difficulty in miniaturization } \\
\text { High cost }\end{array}$ & {$[42,43]$} \\
\hline $\begin{array}{l}\text { Quarz Crystal } \\
\text { Mrobalance } \\
\text { (QCM) }\end{array}$ & Piezoelectricity & $\begin{array}{l}\text { 1.0-ng mass } \\
\text { change }\end{array}$ & $\begin{array}{c}\text { High sensitivity; } \\
\text { Fast response times } \\
\text { Good CMOS compatibility \& } \\
\text { scalability; }\end{array}$ & $\begin{array}{c}\text { Complex fab. Process; } \\
\text { Interference from humidity \& } \\
\text { temp; } \\
\text { Low signal to noise ratio; }\end{array}$ & [44-47] \\
\hline $\begin{array}{l}\text { Surface Acoustic } \\
\text { Wave(SAW) }\end{array}$ & Piezoelectricity & $\begin{array}{l}\text { 1.0-pg mass } \\
\text { chnge }\end{array}$ & $\begin{array}{l}\text { High sensitivity } \\
\text { Good CMOS compatibility \& } \\
\text { scalability }\end{array}$ & $\begin{array}{l}\text { Unstable at higher temp; } \\
\text { Complex readout circuitary }\end{array}$ & [48-50] \\
\hline $\begin{array}{c}\text { Carbon } \\
\text { nanotubes }\end{array}$ & Conductivity & $\begin{array}{l}\text { Low parts per } \\
\text { million }\end{array}$ & $\begin{array}{c}\text { Ultra-sensitive; } \\
\text { Great adsorptive capacity; } \\
\text { Large surface-area-to-volume ratio }\end{array}$ & $\begin{array}{l}\text { Diffculties is fabrication and } \\
\text { repeatability; } \\
\text { High cost }\end{array}$ & [51-53] \\
\hline $\begin{array}{l}\text { Calorimetric } \\
\text { Methods }\end{array}$ & Calorimetry & 10 - 100 ppm & $\begin{array}{c}\text { Stability; } \\
\text { Low cost; } \\
\text { Adequate sensitivity; }\end{array}$ & $\begin{array}{c}\text { Risk of catalyst poisoning and } \\
\text { explosion; } \\
\text { Deficiencies in selectivity }\end{array}$ & {$[54,55]$} \\
\hline
\end{tabular}


ques are utilized for data processing of multivariate response generated by the sensor array [56]. The process of recognition starts after the sensor signals have been acquired and stored in the computer. It can be split into four sequential stages: signal preprocessing, dimensionality reduction, prediction and validation as shown in Figure 1 [57]. Signal preprocessing is the first stage of whole process, focusing on compensating for sensor drift, extracting descriptive parameters from the sensor array response and preparing the feature vector for further processing. The dimensionality reduction stage aims at reducing the initial feature vector dimensionality to avoid problems with high-dimensional datasets. The prediction stage works on data classification, regression, or clustering. Classification solves the problem of identifying an unknown odor sample from previously learned odorants in database. Regression is to predict the properties of analytes, e.g. concentration and quality. Clustering addresses the problem of finding spatial relationships or si- milarities among data samples. The final stage, validation, selects models and parameter settings and estimates the true error rates for a trained model. Figure 2 shows the data processing scheme of pattern analysis techniques in electronic noses.

Pattern-recognition methods can be divided into two categories: unsupervised and supervised learning procedures. For supervised pattern recognition, an unknown odor is tested and classified according to a knowledge base, which requires a priori knowledge about the classes contained within the training sample. In contrast, unsupervised methods learn to separate the different classes from the response vector, discriminating between unknown odor vectors without corresponding odor class descriptions [58].

Principal Components Analysis (PCA) is a commonly used technique of unsupervised pattern-recognition for its fast computing speed. PCA is a linear feature extraction technique which focuses on visualizing the

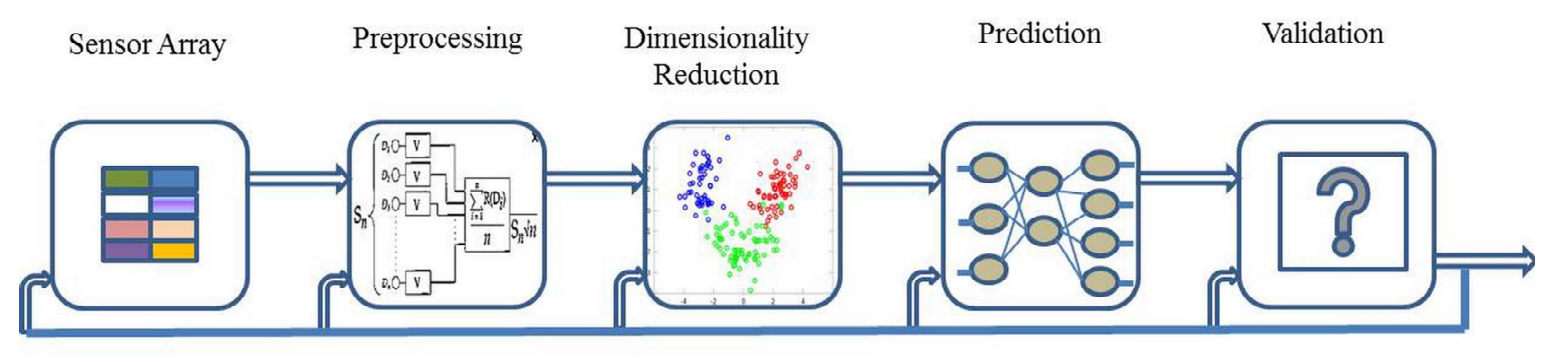

Optimization feedback

Figure 1. Four sequential stages in data processing.

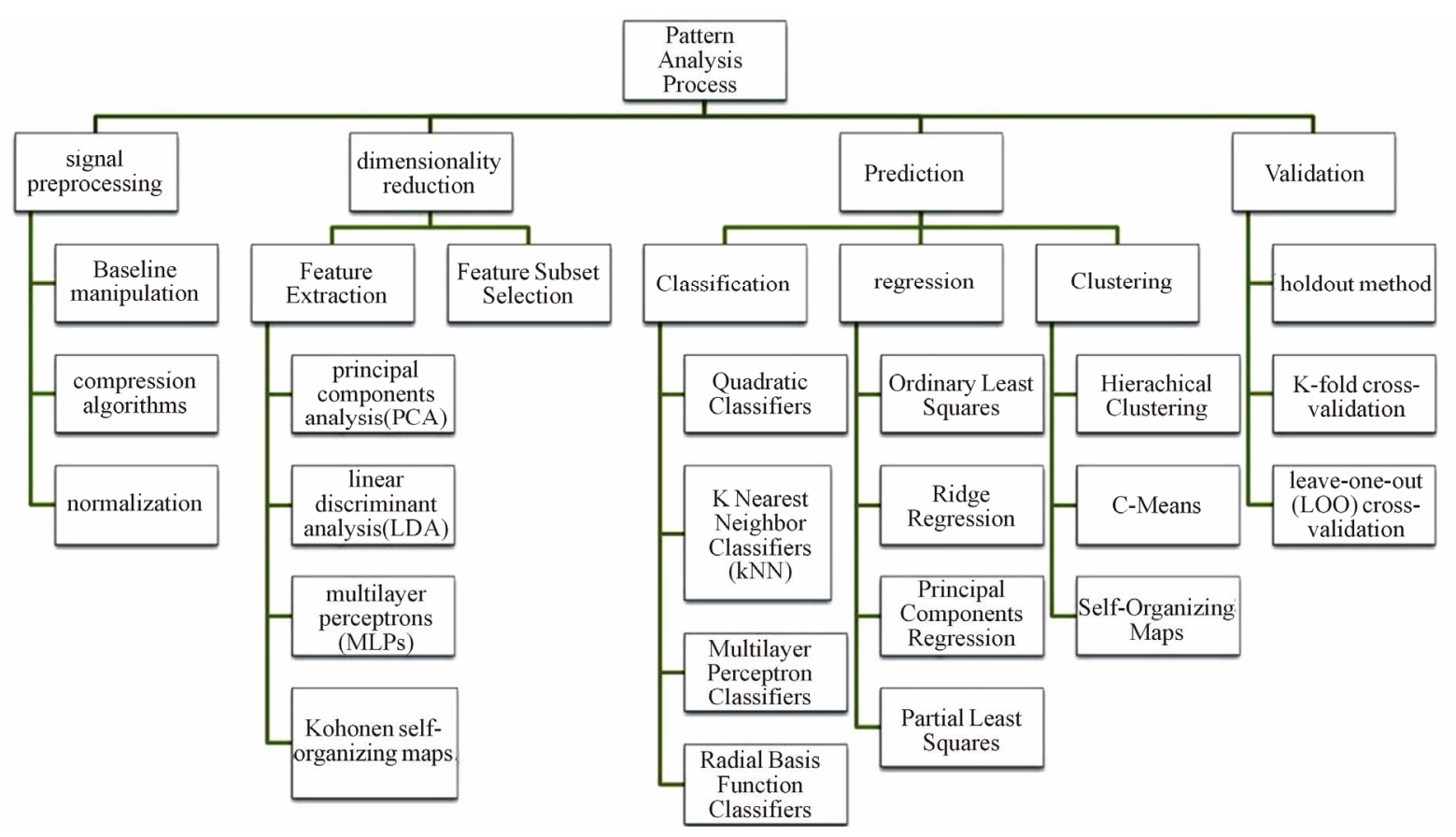

Figure 2. Data processing scheme and available techniques. 
most reliable data cloud within a low dimensional space. By projecting variables onto fewer dimensions, original data can be condensed to a few variables reflecting the most relevant analytical information. This offers an advantage that the classification and regression of unknowns is processed much faster, thus reducing detection time. However, if the sensor output parameters are not linear, interpolation of features may occur in the results of PCA, because PCA is a linear technique that treats all sensors equally, leading to unduly influence the sensors' performance.

Linear Discriminant Analysis (LDA) is a supervised method performing dimensionality reduction while preserving as much class discriminatory information as possible. LDA provides an algorithm to carefully establish a discriminant function for predictors, aiming to achieve maximum separation between data classes. Choi et al. employed a microfluidic device to monitor protein distributions using LDA to quantitatively differentiate the SPR angle patterns on the sensing surfaces with pre-adsorbed proteins [59]. However, when the number of observations is limited compared to the dimension of the feature space, a reliable classifier can be seriously degraded if only using LDA. Hence, it is necessary for a data reduction, e.g. PCA, precede LDA for data classifycation. Aamir and Hasan investigated a biometric identity system using PCA and LDA. It is observed that using PCA and LDA jointly achieved accurate results and significantly decreased the complexity [60].

\section{Applications of Electronic Noses in Clinical diagnosis}

Electronic noses have been developed as a non-invasive, painless and simple screening method for early medical diagnosis to recognize characteristic smells from diseases and bacteria cells. They have shown the ability to detect and distinguish a variety of bacteria and fungi from human body, and identify particular biomarker by characterization of VOCs above microorganisms. Swabs, sputum, serum, feces, breath or urine sampled from the human body can be measured as biomedical samples for diagnosis after a short incubation time or directly in some cases. Table 2 provides a summary of biomarkers and samples that can be detected by electronic noses. A comprehensive analysis of past and recent research findings and developments of electronic nose technologies in medical diagnosis will be presented below and classified by diseases.

\subsection{Cancer Detection}

It is known that dogs have the capability to detect cancer by sniffing the patient's breath which is termed as canine cancer detection. They can identify specific alkanes and aromatic compounds at low concentrations in breath created by a tumor that circulates from the patient's blood to the lungs. Similarly, electronic noses can detect disease marker substances from the human body, thus having the potential of early stage detection for different types of

Table 2. Application of electronic nose on samples and biomarkers for human disease.

\begin{tabular}{|c|c|c|c|}
\hline Disease/Disorder/Infection & Aroma sample source & Associated volatile biomarkers & Ref. \\
\hline Urinary tract infections & Urine & $\begin{array}{c}\text { Staphylococcus aureus, } \\
\text { Escherichia coli, } \\
\text { Proteus mirabilis, } \\
\text { Isovaleric acid, alkanes }\end{array}$ & {$[61-66]$} \\
\hline \multirow{3}{*}{ Tuberculosis } & Sputum & $\begin{array}{c}\text { Mycobacterium tuberculosis, } \\
\text { Mycobacterium avium, } \\
\text { Pseudomonas aeruginosa; }\end{array}$ & [67] \\
\hline & Breath & Oxetane,3-(1-methylethyl)-Dodecane, 4-methyl-Cyclohexane; & {$[68]$} \\
\hline & Lung tissue & PD-1, TIM-3, KLRG-1 & {$[69]$} \\
\hline $\begin{array}{l}\text { Ear, nose, throat } \\
\text { infections }\end{array}$ & Swabs & $\begin{array}{l}\text { Staphylococcus aureus, } \\
\text { Pseudomonas aeruginosa, } \\
\text { Streptococcus pneumonia, } \\
\text { Streptococcus pyogenes, } \\
\text { Haemophilusinfluenzae }\end{array}$ & {$[70-72]$} \\
\hline \multirow[t]{2}{*}{ Asthma } & Human breath & $\begin{array}{c}\text { Pentane, ethane, 8-isoprostane, } \\
\text { nitric oxide, cysteinylleukotrienes, prostaglandin E2 }\end{array}$ & {$[73-82]$} \\
\hline & Sputum & eosinophil cationic protein & {$[83]$} \\
\hline Breast cancer & Human breath & $\begin{array}{l}\text { C4 - C20 alkanes, } \\
\text { monomethylated alkanes }\end{array}$ & {$[84]$} \\
\hline COPD & Human breath & $\begin{array}{c}\mathrm{NO}, \mathrm{H}_{2} \mathrm{O}_{2} \text {, aldehydes, 8-isoprostane, nitrotyrosine, } \\
\text { Leukotriene B4, cytokines }\end{array}$ & {$[85-90]$} \\
\hline Sweaty feet syndrome & Urine, sweat, human breath & Butyric acid, hexanoic acid; trans-3-methyl-2 hexenoic acid & [91] \\
\hline
\end{tabular}


cancers. Recent results showed utility of an electronic nose to smell chemicals related to lung, breast, brain, prostatic, melanoma and pancreatic cancers. However, few biomarkers are available for cancer detection at the present time due to the difficulty in determining which specific VOCs correlate with a cancer type among a vast myriad of possible compounds detected.The detection of lung cancer accounts for most cancer diagnosisby electronic noses since important biomarkers for this disease have been discovered in numerous investigations of VOCs identified from exhaled breath of lung cancer patients. Machado et al. used an electronic nose to identify and discriminate between 14 bronchogenic carcinoma patients and 45 healthy controls. The electronic nose is based on array of 32 polymer composite sensors with the output processed using Savitzky-Golay filtering and baseline correction and then analyzed using PCA. The result demonstrated effective discrimination between samples from patients with lung cancer and those from healthy controls. In validation study, the electronic nose had $71.4 \%$ sensitivity and $91.9 \%$ specificity for detecting lung cancer, positive and negative predictive values were $66.6 \%$ and $93.4 \%$, respectively [92]. Although studies have supported the correlation between the composition of breath and lung cancer, many other diseases can alter the breath composition and interfere with detection, so it is necessary not only to detect generic alterations, but also those specifically consequent to cancer. Based on this fact, Pennazza et al. conducted an experiment to discriminate between lung cancer, diverse lung diseases, reference controls, and most importantly to study the effect of compounds in breath whose concentrations are significantly different with respect to normal populations. The effect of alleged lung cancer typical VOCs (aniline, o-toluidine, and cyclopentane) is investigated by adding VOCs to breaths collected from control individuals to create artificial lung cancer breaths. The analysis of artificial breaths is compared with those of breaths exhaled by patients and healthy controls. Results have shown that the data points of the artificially altered breath samples tend to drift toward the lung cancer group, proving the significance of the role played by these volatile compounds in contribution to lung cancer [93]. Researchers are dedicated to applying electronic noses to other types of cancer. Brain cancer was investigated by Kateb et al. using a Jet Propulsion Laboratory's electronic nose (JPL E-Nose) to discriminate the odor signatures between cultured glioblastoma and melanoma tumor cells, and between chicken heart and chicken liver tissues. The JPL E-Nose consisted of 16 sensors with uniquely coated polymer-carbon composite films and sensed the air in the head space above the cells based on a change in conductivity. The results showed that the JPL E-Nose was able to distinguish between two types of tumor cells and be- tween two types of organ tissue, which could be used as part of multi-modality intraoperative approach for detection and treatment of brain cancers [94]. Horvath was able to discriminate between different VOCs emitted by human grade 3 seropapillary ovarian carcinoma and healthy human Fallopian tube specimens by using an electronic nose. This method has correctly classified 84.4\% of cancer tissues (sensitivity: $84.4 \%$ ) and $86.8 \%$ of the control samples (specificity: 86.8\%) [95].

\subsection{Respiratory Diseases}

The extensive research for non-invasive respiratory disease markers has led to the development of an electronic nose which can distinguish diseases that affect the airway or pulmonary parenchyma [4]. Electronic noses can be applied to identify respiratory bacterial pathogens either in vitro or in vivo or as a potential tool for the identification of patients with COPD, asthma, and Tuberculosis. The analysis of exhaled breath has been proposed as the main option for detection and identification of respiratory diseases, although other approaches exist, e.g. the analysis of blood samples and bacterial culture samples. The breath prints produced by an electronic nose are associated with airway inflammation activity, and provide a molecular basis for disease detection and a personalized pharmacological treatment. Bruins used a commercially available e-nose (diagnose, C-it BV) to detect tuberculosis in exhaled air produced by healthy controls and TB patients. The diagnose device incorporated 12 metaloxide sensors, as4 different sensor types (AS-MLC; AS-MLN; AS-MLK; AS-MLV, Applies Sensors Gmbh) in triplicate. Two studies were conducted to estimate the diagnostic accuracy of the Diagnose analysis, I.e., a Proof of Principle Study (30 participants) and a Validation Study (194 participants). The results showed that the electronic nose can differentiate between TB patients and healthy controls with a sensitivity of $76.5 \%$ and specificity of $87.2 \%$ when identifying TB patients within the entire test population. The research has demonstrated a possibility of an electronic nose as a portable and fasttime-to-result device to screen search for TB cases in rural areas, without the need for highly-skilled operators or a hospital center infrastructure [96]. Similarly, Dragonieri employed the Cyranose 320 electronic nose to discriminate between patients with non-small cell lung cancer, patients with COPD, and healthy controls. Results have shown that smell prints from non-small cell lung cancer patients clustered distinctly from those of COPD subjects and healthy controls [97]. From further study, it is known that patients with COPD produce certain VOCs distinct from those produced by patients with lung cancer. 


\subsection{Urinary Tract Infections}

Urinary Tract Infection (UTI) is one of the most prevalent infectious diseases with 3 million UTI cases each year in the USA alone [98]. The urinary system includes the kidneys, ureters, bladder and urethra. Most UTI affects the lower urinary tract known as a simple cysititis (a bladder infection), which is not serious unless it spreads to the upper tract and develops into pyelonephritis; thus, early diagnosis for UTI is important and the application of an electronic nose opens the gate for on-line and simple UTI diagnosis. Approximately 80\% of uncomplicated UTIs are caused by Escherichia coli, $20 \%$ by enteric pathogens such as Enterococci, Klebsiellae, Proteus spp., coagulase (-) Staphylococci and fungal opportunistic pathogens such as Candida albicans [99, 100]. Electronic noses can diagnose UTIs by examining the volatile compounds produced by bacterial contaminants in urine samples. Based on this fact, Pavlou et al. employed an electronic nose consisting of 14 conducting polymer sensors to distinguish between normal urine, Escherichia coli infected, Proteus spp. and Staphylococcus spp. They also investigated the feasibility of using the electronic nose to identify unknown UTI cases. The study has shown the potential for early detection of microbial contaminants related to UTI using an electronic nose, which might be applied in rapid systems for use in clinical practice [61].

\section{Concluding Remarks and Future Challenges}

This review gives a glimpse of what has been achieved to date and what might be possible in the future through the use of electronic noses in clinical diagnosis. Versatile sensing techniques of electronic noses continue to open up new possibilities for assays in parallel, real-time, accurate and fast detection in clinical practice, allowing earlier detections of diseases and evaluations of patient conditions before symptoms appear. However, as several studies have shown, sensor-based electronic noses generally suffer from significant weaknesses that limit their widespread application in clinical diagnosis, such as sensitivity to temperature, humidity, interference with other gases and the release of poisonous products. Adopting appropriate sample pretreatment and pre-concentration techniques can increase the sensitivity of diagnosis; furthermore, the use of filters and separation units can increase the selectivity and reduce interfering substances [1]. However, this leads to an increase in the complexity of the electronic nose system, which is undesirable for widespread clinical practice. The research and development of electronic noses will still focus on epidemic diseases such as various cancers, tuberculosis (TB), autoimmune deficiency syndrome (AIDS), and other major diseases responsible for current world pandemics [101]. Breath analysis is an attractive procedure for electronic noses to predict disease because it is non-invasive and sampling methods are simple. However, one of the major proficiencies of diagnostic breath analysis is the difficulty in discovering the relationship between identified marker compounds with a pathology, since in most cases specific metabolic pathways are unknown [102]. Once these difficulties are resolved, the application of electronic noses could make up a vital part in monitoring disease epidemiology.

\section{REFERENCES}

[1] F. Rock, N. Barsan and U. Weimar, "Electronic Nose: Current Status and Future Trends,” Chemical Reviews, Vol. 108, No. 2, 2008, pp. 705-725. doi:10.1021/cr068121q

[2] A. P. F. Turner and N. Magan, "Electronic Noses and Disease Diagnostics," Nature Reviews, Vol. 2, No. 2, 2004, pp. 161-166. doi:10.1038/nrmicro823

[3] J. W. Gardner and P. N. Bartlett, "A Brief History of Electronic Noses,” Sensors and Actuators B, Vol. 18-19, No. 1-3, 1994, pp. 211-220.

[4] J. L. Valera, B. Togores and B. G. Cosio, "Use of the Electronic Nose for Diagnosing Respiratory Diseases," Archivos de Bronconeumología, Vol. 48, No. 6, 2012, pp. 187-188. doi:10.1016/j.arbr.2012.03.002

[5] M. Peris and L. Escuder-Gilabert, "A 21st Century Technique for Food Control: Electronic Noses,” Analytica Chimica Acta, Vol. 638, No. 1, 2009, pp. 1-15. doi:10.1016/j.aca.2009.02.009

[6] M. Bernabei, G. Pennazza, M. Santonico, C. Corsi, C. Roscioni, R. Paolesse, C. D. Natale and A. D’Amico, “A Preliminary Study on the Possibility to Diagnose Urinary Tract Cancers by an Electronic Nose," Sensors \& Actuators: B. Chemical, Vol. 131, No. 1, 2008, pp. 1-4. doi:10.1016/j.snb.2007.12.030

[7] S. Kanoh, H. Kobayashi, and K. Motoyoshi, "Exhaled Ethane: An in Vivo Biomarker of Lipid Peroxidation in Interstitial Lung Diseases,” Chest, Vol. 128, No. 4, 2005, pp. 2387-2392. doi:10.1378/chest.128.4.2387

[8] E. Dixon, C. Clubb, S. Pittman, L. Ammann, Z. Rasheed, N. Kazmi, A. Keshavarzian, P. Gillevet, H. Rangwala and R. D. Couch, "Solid-Phase Microextraction and the Human Fecal VOC Metabolome,” PLOS ONE, Vol. 6, No. 4, 2011, pp. 371-380. doi:10.1371/journal.pone.0018471

[9] A. Nordberg, M. Hansson, I. Sundh, E. Nordkvist, H. Carisson and B. Mathisen, "Monitoring of a Biogas Process Using Electronic Gas Sensors and Near-Infrared Spectroscopy (NIR)," Water Science and Technology, Vol. 41, No. 3, 2000, pp. 1-8.

[10] J. Hartmann, J. Auge and P. Hauptmann, "Using the Quartz-Crystal-Microbalance Principle for Gas Detection with Reversible and Irreversible Sensors,” Sensors and Actuators B, Vol. 19, No. 1-3, 1994, pp. 429-433. doi:10.1016/0925-4005(93)01025-Y 
[11] J. Ricco, R. M. Crooks and G. C. Osbourn, "Surface Acoustic Wave Chemical Sensor Arrays: New Chemically Sensitive Interfaces Combined with Novel Cluster Analysis to Detect Volatile Organic Compounds and Mixtures," Accounts of Chemical Research, Vol. 31, No. 5, 1998, pp. 289-296. doi:10.1021/ar9600749

[12] B. C. Sisk and N. S. Lewis, "Estimation of Chemical and Physical Characteristics of Analyte Vapors Through Analysis of the Response Data of Arrays of PolymerCarbon Black Composite Vapor Detectors," Sensors and Actuators B, Vol. 96, No. 1, 2003, pp. 268-282. doi:10.1016/S0925-4005(03)00543-4

[13] K. J. Albert, D. R. Walt, D. S. Gill and T. C. Pearce, “Optical Multibead Arrays for Simple and Complex Odor Discrimination,” Analytical Chemistry, Vol. 73, No. 11, 2001, pp. 2501-2508. doi:10.1021/ac001137a

[14] A. Kolmakov and M. Moskovits, "Chemical Sensing and Catalysis by Onedimensional Metal-Oxide Nanostructures," Annual Review of Materials Research, Vol. 34, 2004, pp. 151-180. doi:10.1146/annurev.matsci.34.040203.112141

[15] J. W. Gardner and P. N. Bartlett, "Electronic Noses: Principles and Applications," Oxford University Press, Oxford, 1999.

[16] T. Maekawa, K. Suzuki, T. Takada, T. Kobayashi and M. Egashira, "Odor Identification Using a $\mathrm{SnO}_{2}$-Based Sensor Array,” Sensors and Actuators B, Vol. 80, No. 1, 2001, pp. 51- 58.

[17] J. Getino, L. Ares, J. I. Robla, M. C. Horrillo, I. Sayago, M. J. Fernandez, J. Rodrigo and J. Gutierrez, "Environmental Applications of Gas Sensor Arrays: Combustion Atmospheres and Contaminated Soils," Sensors and Actuators B, Vol. 59, No. 2, 1999, pp. 249-254. doi:10.1016/S0925-4005(99)00229-4

[18] S. Zampolli, I. Elmi, F. Ahmed, M. Passini, G. C. Cardinali, S. Nicoletti and L. Dori, “An Electronic Nose Based on Solid State Sensor Arrays for Low-Cost Indoor Air Quality Monitoring Applications,” Sensors and Actuators B, Vol. 101, No. 1-2, 2004, pp. 39-46.

[19] S. Ehrmann, J. Jungst, J. Goschnick and D. Everhard, "Application of a Gas Sensor Microarray to Human Breath Analysis," Sensors and Actuators B, Vol. 65, No. 1, 2000, pp. 247-249.

[20] P. Moseley, "Materials Selection for Semiconductor Gas Sensors," Sensors and Actuators B: Chemical, Vol. 6, No. 1-3, 1992, pp. 149-156. doi:10.1016/0925-4005(92)80047-2

[21] N. White and J. D. Turner, "Thick-Film Sensors: Past, Present and Future, Measurement," Science and Technology, Vol. 8, No. 1, 1997, pp. 1-20.

[22] D. Kohl, "Function and Applications of Gas Sensors," Journal of Physics D: Applied Physics, Vol. 34, No. 19, 2001, pp. R125-R149. doi:10.1088/0022-3727/34/19/201

[23] S. Aathithan, J. C. Plant, A. N. Chaudry and G. L. French, "Diagnosis of Bacteriuria by Detection of Volatile Organic Compounds in Urine Using an Automated Headspace Analyzer with Multiple Conducting Polymer Sensors,” Journal of Clinical Microbiology, Vol. 39, No. 7,
2001, pp. 2590-2593.

doi:10.1128/JCM.39.7.2590-2593.2001

[24] I. Eisele, T. Doll and M. Burgmair, "Low Power Gas Detection with Fet Sensors," Sensors and Actuators B: Chemical, Vol. 78, No. 1-3, 2001, pp. 19-25. doi:10.1016/S0925-4005(01)00786-9

[25] R. Fend, A. H. J. Kolk, C. Bessant, P. Buijtels, P. R. Klatser, A. C. Woodman, "Prospects for Clinical Application of Electronic-Nose Technology to Early Detection of Mycobacterium tuberculosis in culture and sputum," Journal of Clinical Microbiology, Vol. 44, No. 6, 2006, pp. 2039-2045. doi:10.1128/JCM.01591-05

[26] H. Bai and G. Shi, "Gas Sensors Based on Conducting Polymers,” Sensors, Vol. 7, No. 3, 2007, pp. 267-307. doi:10.3390/s7030267

[27] D. James, S. M. Scott, Z. Ali and W. T. O’Hare, “Chemical Sensors for Electronic Nose Systems," Microchimica Acta, Vol. 149, No. 1-2, 2005, pp. 1-17. doi:10.1007/s00604-004-0291-6

[28] E. H. Oh, H. S. Song and T. H. Park, "Recent Advances in Electronic and Bioelectronic Noses and Their Biomedical Applications,” Enzyme and Microbial Technology, Vol. 48, No. 6, 2011, pp.427-437. doi:10.1016/j.enzmictec.2011.04.003

[29] S. Kladsomboon, M. Lutz, T. Pongfa and T. Kerdcharoen, "An Optical Artificial Nose System for Odor Classifications Based on LED Arrays," Proceedings of the 8th International Conference on Electrical Engineering/Electronics, Bangkok, 17-19 May 2011, pp. 145-148.

[30] A. Eambaipreuk, "Breath Monitoring Based on the Optical Electronic Nose System,” Proceedings of Biomedical Engineering International Conference (BMEICON), Bangkok, 29-31 January 2012, pp. 63-66.

[31] T. C. Pearce, S. S. Schiffman, H. T. Nagle and J. W. Gardner, "Handbook of Machine Olfaction: Electronic Nose Technology," ChemPhysChem, Vol. 4, No. 11, 2003, pp. 1265-1266. doi:10.1002/cphc.200390115

[32] Y. Mendelson, “The Biomedical Engineering Handbook,” CRC Press, LLC, Florida, 2000.

[33] C. Wang and P. Sahay, "Breath Analysis Using Laser Spectroscopic Techniques: Breath Biomarkers, Spectral Fingerprints, and Detection Limits,” Sensors, Vol. 9, No. 10, 2009, pp. 8230-8262. doi:10.3390/s91008230

[34] K. Mitsubayashi, T. Minamide, K. Otsuka, H. Kudo and H. Saito, "Optical Bio-Sniffer for Methyl Mercaptan in Halitosis,” Analytica Chimica Acta, Vol. 573, 2006, pp. 75-80. doi:10.1016/j.aca.2006.01.062

[35] S. Choi, Y. Yang, J. Chae, "Surface Plasmon Resonance Protein Sensor Using Vroman Effect," Biosensors and Bioelectronics, Vol. 24, No. 4, 2008, pp. 893-899. doi:10.1016/j.bios.2008.07.036

[36] P. Wang, X. Chen, F. Xu, D. Lu, W. Cai , K. Ying, Y. Wang and Y. Hu, "Development of Electronic Nose for Diagnosis of Lung Cancer at Early Stage,” Proceedings of the 5th International Conference on Information Technology and Application in Biomedicine, Shenzhen, 30-31 May 2008, pp. 589-591.

[37] W. Feng, R. Hettiarachchi1, S. Sato, K. Kakushima, M. 
Niwa, H. Iwai, K. Yamada and K. Ohmoril, "Advantages of Silicon Nanowire Metal-Oxide-Semiconductor Field-Effect Transistors over Planar Ones in Noise Properties,” Japanese Journal of Applied Physics, Vol. 51, No. 4, 2012, Article ID: 04DC06.

[38] A. Oprea, N. Bârsan and U. Weimar, "Characterization of Granular Metal Oxide Semiconductor Gas Sensitive Layers by Using Hall Effect Based Approaches,” Journal of Physics D: Applied Physics, Vol. 40, No. 23, 2007, pp. 7217-7237. doi:10.1088/0022-3727/40/23/S05

[39] J. Lee, W. D. Kim and H. Lim, "Facile Fabrication of Conducting Polymer Nanowire Based Field Effect Transistor with Controlled Shape and Position,” Microelectronic Engineering, Vol. 98, 2012, pp. 382-385. doi:10.1016/j.mee.2012.07.012

[40] M. E. Vaschetto, A. P. Monkman and M. Springborg, "First-Principles Studies of Some Conducting Polymers: PPP, PPy, PPV, PPyV, and PANI,” Journal of Molecular Structure (Theochem), Vol. 468, No. 3, 1999, pp. 181191. doi:10.1016/S0166-1280(98)00565-X

[41] C. Luo and A. Chakraborty, "Effects of Dimensions on the Sensitivity of a Conducting Polymer Microwiresensor,” Microelectronics Journal, Vol. 40, No. 6, 2009, pp. 912-920. doi:10.1016/j.mejo.2008.11.064

[42] M. L. Gabriele, G. Wollstein, H. Ishikawa, J. Xu, J. Kim, L. Kagemann, L. S. Folio and J. S. Schuman, "Three dimensional Optical Coherence Tomography Imaging: Advantages and Advances," Progress in Retinal and Eye Research, Vol. 29, No. 6, 2010, pp. 556-579. doi:10.1016/j.preteyeres.2010.05.005

[43] M. Blumentritt, K. Melhorn, J. Flachsbarth, M. Kroener, W. Kowalsky and H. H. Johannes, "A Novel Fabrication Method of Fiber-Optical Planar Transmission Sensors for Monitoring $\mathrm{pH}$ in Concrete Structures," Sensors and Actuators B, Vol. 131, No. 2, 2008, pp. 504-508. doi:10.1016/j.snb.2007.12.034

[44] A. L. Smith and H. M. Shirazi, "Principles of Quartz Crystal Microbalance/Heat Conduction Calorimetry: Measurement of the Sorption Enthalpy of Hydrogen in Palladium,” Thermochimica Acta, Vol. 432, No. 2, 2005, pp. 202-211. doi:10.1016/j.tca.2005.03.017

[45] B. Pejcic, E. Crookea, C. M. Doherty, A. J. Hill, M. Myers, X. Qia and A. Rossa, "The Impact of Water and Hydrocarbon Concentration on the Sensitivity of a Polymer-Based Quartz Crystal Microbalance Sensor for Organic Compounds,” Analytica Chimica Acta, Vol. 703, No. 1, 2011, pp. 70-79.

[46] B. Pejcic, C. Barton, E. Crooke, P. Eadington, E. Jee and A. Ross, "Hydrocarbon Sensing. Part 1: Some Important Aspects about Sensitivity of a Polymer-Coated Quartz Crystal Microbalance in the Aqueous Phase," Sensors and Actuators B, Vol. 135, No. 2, 2009, pp. 436-443. doi:10.1016/j.snb.2008.09.044

[47] G. Xiea, P. Suna, X. Yana, X. Dua and Y. Jianga, "Fabrication of Methane Gas Sensor by Layer-by-Layer SelfAssembly of Polyaniline/PdO Ultra Thin Films on Quartz Crystal Microbalance," Sensors and Actuators B: Chemical ,Vol. 145, No. 1, 2010, pp. 373-377. doi:10.1016/j.snb.2009.12.035
[48] F. D. Lai and H. M. Huang, "Fabrication of High Frequency and Low-Cost Surface-Acoustic Wave Filters Using Near Field Phase Shift Photolithography," Microelectronic Engineering, Vol. 83, No. 4, 2006, pp. 1407-1409. doi:10.1016/j.mee.2006.01.106

[49] S. Krishnamoorthy and A. A. Iliadis, "Properties of High Sensitivity ZnO Surface Acoustic Wave Sensors on $\mathrm{SiO}_{2} /$ (100) Si Substrates," Solid-State Electronics, Vol. 52, No. 11, 2008, pp. 1710-1716. doi:10.1016/j.sse.2008.06.039

[50] L. Fan, H. Ge, S. Y. Zhang, H. Zhang and J. Zhu, "Optimization of Sensitivity Induced by Surface Conductivity and Sorbed Mass in Surface Acoustic Wave Gas Sensors," Sensors and Actuators B: Chemical, Vol. 171-172, 2012, pp. 1272-1276. doi:10.1016/j.snb.2012.05.046

[51] M. H. Ervina, B. S. Millera, B. Hanrahana, B. Mailly and T. Palacios, "A Comparison of Single-Wall Carbon Nanotube Electrochemical Capacitor Electrode Fabrication Methods," Electrochimica Acta, Vol. 65, 2012, pp. 37-43. doi:10.1016/j.electacta.2012.01.060

[52] H. Kang, S. Lim, N. Park, K.-Y. Chun and S. Baik, "Improving the Sensitivity of Carbon Nanotube Sensors by Benzene Functionalization,” Sensors and Actuators B: Chemical, Vol. 147, No. 1, 2010, pp. 316-321. doi:10.1016/j.snb.2010.03.028

[53] J. Zheng, Q. Q. Zhang, X. C. He, M. J. Gao, X. F. Ma and G. Li, "Nanocomposites of Carbon Nanotube (CNTs)/ $\mathrm{CuO}$ with High Sensitivity to Organic Volatiles at Room Temperature,” Procedia Engineering, Vol. 36, 2012, pp. 235-245. doi:10.1016/j.proeng.2012.03.036

[54] V. Casey, J. Cleary, G. D. Arcy and J. B. McMonagle, "Calorimetric Combustible Gas Sensor Based on a Planar Thermopile Array: Fabrication, Characterisation, and Gas Response,” Sensors and Actuators B: Chemical, Vol. 96, No. 1, 2003, pp. 114-123. doi:10.1016/S0925-4005(03)00510-0

[55] P. Kirchner, J. Oberländer, P. Friedrich, J. Berger, G. Rysstad, M. Keusgen and M. J. Schöning, "Realisation of A Calorimetric Gas Sensor on Polyimide Foil for Applications in Aseptic Food Industry," Sensors and Actuators B: Chemical, Vol. 170, 2012, pp.60-66. doi:10.1016/j.snb.2011.01.032

[56] E. L. Hines, P. Boilot, J. L. W. Gardner and M. A. Gongora, "Pattern Analysis for Electronic Noses," In: T. Pearce, et al., Eds., Handbook of Machine Olfaction: Electronic Nose Technology, Wiley-VCH, Weinheim, 2003, pp. 130-160.

[57] R. O. Gutierrez, "Pattern Analysis for Machine Olfaction: A Review,” IEEE Sensors Journal, Vol. 2, No. 3, 2006, pp. 189-202.

[58] D. L. G. González, R. Aparicio and G. Y. Aceites, "Sensors: From Biosensors to the Electronic Nose," Grasas y Aceites, Vol. 53, No. 1, 2002, pp. 96-114.

[59] S. Choi, S. Huang, J. Li and J. Chae, "Monitoring Protein Distributions Based on Patterns Generated by Protein Adsorption Behavior in a Microfluidic Channel," Lab Chip, Vol. 11, 2011, pp. 3681-3688. doi:10.1039/c1lc20680j

[60] K. Aamir and F. Hasan, "Principal Component Analysis- 
Linear Discriminant Analysis Feature Extractor for Pattern Recognition,” IJCSI International Journal of Computer Science Issues, Vol. 8, No. 6, 2011, p. 267.

[61] A. K. Pavlou, N. Magan, C. McNulty, J. M. Jones, D. Sharp, J. Brown and A. P. F. Turner, "Use of an Electronic Nose System for Diagnoses of Urinary Tract Infections," Biosensors and Bioelectronics, Vol. 17, No. 10, 2002, pp. 893-899. doi:10.1016/S0956-5663(02)00078-7

[62] S. Aathithan, J. C. Plant, A. N. Chaudry and G. L. French, "Diagnosis of Bacteriuria by Detection of Volatile Organic Compounds in Urine Using an Automated Headspace Analyzer with Multiple Conducting Polymer Sensors,” Journal of Clinical Microbiology, Vol. 39, No. 7, 2001, pp. 2590-2593. doi:10.1128/JCM.39.7.2590-2593.2001

[63] N. Guernion, N. M. Ratcliffe, P. T. Spencer-Phillips and R. A. Howe, "Identifying Bacteria in Human Urine: Current Practice and the Potential for Rapid, Near-Patient Diagnosis by Sensing Volatile Organic Compounds," Clinical Chemistry and Laboratory Medicine, Vol. 39, No. 10, 2001, pp. 893-906. doi:10.1515/CCLM.2001.146

[64] V. Kodogiannis and E. Wadge, "The Use of Gas-Sensor Arrays to Diagnose Urinary Tract Infections,” International Journal of Neural Systems, Vol. 15, No. 5, 2005, pp. 363-376. doi:10.1142/S0129065705000347

[65] J. W. Yates, M. J. Chappell, J. W. Gardner, C. S. Dow, C. Dowson, A. Hamood, F. Bolt and L. Beeby, "Data Reduction in Headspace Analysis of Blood and Urine Samples for Robust Bacterial Identification,” Computer Methods and Programs in Biomedicine, Vol. 79, No. 3, 2005, pp. 259-271.doi:10.1016/j.cmpb.2005.04.003

[66] P. Ying, G. A. Sonn, M. L. Y. Sin, K. E. Mach, M. Shih, V. Gau, P. K. Wong and J. C. Liao, "Electrochemical Immunosensor Detection of Urinary Lactoferrin in Clinical Samples for Urinary Tract Infection Diagnosis,” Biosensors and Bioelectronics, Vol. 26, No. 2, 2010, pp. 649-654. doi:10.1016/j.bios.2010.07.002

[67] A. K. Pavlou, N. Magan, J. M. Jones, J. Brown, P. Klatser and A. P. Turner, "Detection of Mycobacterium Tuberculosis (TB) in Vitro and in Situ Using an Electronic Nose in Combination with a Neural Network System," Biosensors and Bioelectronics, Vol. 20, No. 3, 2004, pp. 538-544. doi:10.1016/j.bios.2004.03.002

[68] M. Phillips, V. Basa-Dalay, G. Bothamley, R. N. Cataneo, P. K. Lam, M. P. R. Natividad, P. Schmitt and J. Wai, "Breath Biomarkers of Active Pulmonary Tuberculosis," Tuberculosis, Vol. 90, No. 2, 2010, pp. 145-151. doi:10.1016/j.tube.2010.01.003

[69] T. M. Henao, S. M. Irwin, S. Shang, D. Ordway and I. M. Orme, "T Lymphocyte Surface Expression of Exhaustion Markers as Biomarkers of the Efficacy of Chemotherapy for Tuberculosis,” Tuberculosis, Vol. 91, No. 4, 2011, pp. 308-313. doi:10.1016/j.tube.2011.04.001

[70] S. Y. Lai, O. F. Deffenderfer, W. Hanson, M. P. Phillips and E. R. Thaler, "Identification of Upper Respiratory Bacterial Pathogens with the Electronic Nose," Laryngoscope, Vol. 112, No. 6, 2002, pp. 975-979. doi:10.1097/00005537-200206000-00007

[71] M. E. Shykhon, D. W. Morgan, R. Dutta, E. L. Hines and
J. W. Gardner, “Clinical Evaluation of the Electronic Nose in the Diagnosis of Ear, Nose and Throat Infection: A Preliminary Study," The Journal of Laryngology \& Otology, Vol. 118, No. 9, 2004, pp. 706-709. doi:10.1258/0022215042244660

[72] R. Dutta, D. Morgan, N. Baker, J. W. Gardner and E. L. Hines, "Identification of Staphylococcus Aureus Infections in Hospital Environment: Electronic Nose Based Approach," Sensors and Actuators B: Chemical, Vol. 109, No. 2, 2005, pp. 355-362. doi:10.1016/j.snb.2005.01.013

[73] C. O. Olopade, M. Zakkar, W. I. Swedler and I. Rubinstein, "Exhaled Pentane Levels in Acute Asthma,” Chest Journal, Vol. 111, No. 4, 1997, pp. 862-865. doi:10.1378/chest.111.4.862

[74] P. Montuschi, M. Corradi, G. Ciabattoni, J. Nightingale, S. A. Kharitonov and P. J. Barnes, "Increased 8-Isoprostane, a Marker of Oxidative Stress, in Exhaled Condensate of Asthma Patients," American Journal of Respiratory and Critical Care Medicine, Vol. 160, No. 1, 1999, pp. 216-220. doi:10.1164/ajrccm.160.1.9809140

[75] P. Paredi, S. A. Kharitonov and P. J. Barnes, "Elevation of Exhaled Ethane Concentration in Asthma," American Journal of Respiratory and Critical Care Medicine, Vol. 162, No. 4, 2000, pp. 1450-1454. doi:10.1164/ajrccm.162.4.2003064

[76] A. D. Smith, J. O. Cowan, S. Filsell, C. McLachlan, G. Monti-Sheehan, P. Jackson and D. R. Taylor, "Diagnosing Asthma: Comparisons between Exhaled Nitric Oxide Measurements and Conventional Tests," American Journal of Respiratory and Critical Care Medicine, Vol. 169, No. 4, 2004, pp. 473-478. doi:10.1164/rccm.200310-13760C

[77] S. Dragonieri, R. Schot, B. J. Mertens, S. C. Le, S. A. Gauw, A. Spanevello, O. Resta, N. Willard, T. Vink, K. Rabe, E. Bel and P. Sterk, "An Electronic Nose in the Discrimination of Patients with Asthma and Controls," The Journal of Allergy and Clinical Immunology, Vol. 120, No. 4, 2007, pp. 856-862. doi:10.1016/j.jaci.2007.05.043

[78] K. Kostikas, G. Papatheodorou, K. Psathakis, P. Panagou and S. Loukides, "Prostaglandin E2 in the Expired Breath Condensate of Patients with Asthma," European Respiratory Journal, Vol. 22, No. 5, 2003, pp. 743-747. doi:10.1183/09031936.03.00000603

[79] K. Kostikas, M. Gaga, G. Papatheodorou, T. Karamanis, D. Orphanidou and S. Loukides, "Leukotriene B4 in Exhaled Breath Condensate and Sputum Supernatant in Patients with COPD and Asthma," Chest Journal, Vol. 127, No. 5, 2005, pp. 1553-1559. doi:10.1378/chest.127.5.1553

[80] G. E. Carpagnano, M. P. F. Barbaro, O. Resta, E. Gramiccioni, N. V. Valerio, P. Bracciale and G. Valerio, "Exhaled Markers in the Monitoring of Airways Inflammation and Its Response to Steroid's Treatment in Mild Persistent Asthma,” European Journal of Pharmacology, Vol. 519, No. 1-2, 2005, pp. 175-181. doi:10.1016/j.ejphar.2005.06.034

[81] A. M. Fortuna, T. Feixas, M. González and P. Casan, "Diagnostic Utility of Inflammatory Biomarkers in Asth- 
ma: Exhaled Nitric Oxide and Induced Sputum Eosinophil Count," Respiratory Medicine, Vol. 101, No. 11, 2007, pp. 2416-2421. doi:10.1016/j.rmed.2007.05.019

[82] J. S. Debley, E. S. Cochrane, G. J. Redding and E. R. Carter, "Lung Function and Biomarkers of Airway Inflammation during and after Hospitalization for Acute Exacerbations of Childhood Asthma Associated with Viral Respiratory Symptoms," Annals of Allergy, Asthma \& Immunology, Vol. 109, No. 2, 2012, pp. 114-120. doi:10.1016/j.anai.2012.06.004

[83] N. Snell and P. Newbold, "The Clinical Utility of Biomarkers in Asthma and COPD," Current Opinion in Pharmacology, Vol. 8, No. 3, 2008, pp. 222-235. doi:10.1016/j.coph.2008.04.001

[84] M. Phillips, R. N. Cataneo, B. A. Ditkoff, P. Fisher, J. Greenberg, R. Gunawardena, C. S. Kwon, F. RahbariOskoui and C. Wong, "Volatiles Markers of Breast Cancer in the Breath," The Breast Journal, Vol. 9, No. 3, 2003, pp. 184-191. doi:10.1046/j.1524-4741.2003.09309.x

[85] M. Corradi, A. Pesci, R. Casana, R. Alinovi, M. Goldoni, M. V. Vittoria and A. Cuomo, "Nitrate in Exhaled Breath Condensate of Patients with Different Airway Diseases," Nitric Oxide-Biology and Chemistry, Vol. 8, No. 1, 2003, pp. 26-30.

[86] B. Balint, S. A. Kharitonov, T. Hanazawa, L. E. Donnelly, P. L. Shah, M. E. Hodson and P. J. Barnes, "Increased Nitrotyrosine in Exhaled Breath Condensate in Cystic Fibrosis,” European Respiratory Journal, Vol. 17, No. 6, 2001, pp. 1201-1207.doi:10.1183/09031936.01.00072501

[87] M. Corradi, M. Majori, G. C. Cacciani, G. F. Consigli, E. de’Munari and A. Pesci, "Increased Exhaled Nitric Oxide in Patients with Stable Chronic Obstructive Pulmonary Disease,” Thorax, Vol. 54, No. 7, 1999, pp. 572-575. doi:10.1136/thx.54.7.572

[88] W. J. van Beurden, G. A. Harff, P. N. R. Dekhuijzen, M. J. van den Bosch, J. P. Creemers and F. W. Smeenk, “An Efficient and Reproducible Method for Measuring Hydrogen Peroxide in Exhaled Breath Condensate," Respiratory Medicine, Vol. 96, No. 3, 2002, pp. 197-203. doi:10.1053/rmed.2001.1240

[89] Z. L. Borrill, R. C. Starkey and S. D. Singh, "Variability of Exhaled Breath Condensate Leukotriene B4 and 8-Isoprostane in COPD Patients," International Journal of Chronic Obstructive Pulmonary Disease, Vol. 2, No. 1, 2007, pp. 71-76.

[90] W. J. van Beurden, P. N. Dekhuijzen, G. A. Harff and F. W. Smeenk, "Variability of Exhaled Hydrogen Peroxide in Stable COPD Patients and Matched Healthy Controls,” Respiration, Vol. 69, No, 3, 2002, pp. 211-216. doi:10.1159/000063622

[91] J. B. Sidbury, E. K. Smith and W. Harlan, “An Inborn Error of Short-Chain Fatty Acid Metabolism: The Odor of Sweaty Feet Syndrome," The Journal of Pediatrics,
Vol. 70, No. 1, 1967, pp. 8-15. doi:10.1016/S0022-3476(67)80160-4

[92] R. F. Machado, D. Laskowski, O. Deffenderfer, et al., "Detection of Lung Cancer by Sensor Array Analyses of Exhaled Breath," American Journal of Respiratory and Critical Care Medicine, Vol. 171, No. 11, 2005, pp. 1286-1291. doi:10.1164/rccm.200409-1184OC

[93] D. A. Pennazza, M. Santonico, E. Martinelli, C. Roscioni and G. Galluccio, "An Investigation on Electronic Nose Diagnosis of Lung Cancer,” Lung Cancer, Vol. 68, No. 2, 2010, pp. 170-176. doi:10.1016/j.lungcan.2009.11.003

[94] B. Kateb, M. A. Ryan, M. L. Homer, L. M. Lara, Y. Yin, K. Higa and M. Y. Chen, "Sniffing Out Cancer Using the JPL Electronic Nose: A Pilot Study of a Novel Approach to Detection and Differentiation of Brain Cancer," NeuroImage, Vol. 47, No. S2, 2009, pp. T5-T9. doi:10.1016/j.neuroimage.2009.04.015

[95] G. Horvath, J. Chilo and T. Lindblad, "Different Volatile Signals Emitted by Human Ovarian Carcinoma and Healthy Tissue,” Future Oncology, Vol. 6, No. 7, 2010, pp. 1043-1049. doi:10.2217/fon. 10.60

[96] M. Bruins, Z. Rahimc, A. Bos, W. W. van de Sande, H. P. Endtz and A. van Belkum, "Diagnosis of Active Tuberculosis by E-Nose Analysis of Exhaled Air," Tuberculosis, Vol. 93, No. 2, 2012, pp. 1-7.

[97] S. Dragonieri, J. T. Annema, R. Schot, M. P. C. van der Schee, A. Spanevello, P. Carratú, O. Resta, K. F. Rabe and P. J. Sterk, “An Electronic Nose in the Discrimination of Patients with Non-Small Cell Lung Cancer and COPD,” Lung Cancer, Vol. 64, No. 2, 2009, pp. 166-170. doi:10.1016/j.lungcan.2008.08.008

[98] M. Schaechter, G. Medoff and B. I. Eisenstein, "Mechanisms of Microbial Disease,” Lippincott Williams \& Wilkins., Baltimore, 1999.

[99] O. Honkinen, O. Lehtonen, O. Ruuskanen, P. Huovinen and J. Mertsola, "Cohort Study of Bacterial Species Causing Urinary Tract Infection and Urinary Tract Abnormalities in Children,” British Medical Journal, Vol. 318, No. 7186, 1999, pp. 770-771. doi:10.1136/bmj.318.7186.770

[100] S. Krcmery, M. Dubrava and V. Krcmery Jr, "Fungal Urinary Infections in Patients at Risk,” International Journal of Antimicrobial Agents, Vol. 11, No. 3, 1999, pp. 289-291. doi:10.1016/S0924-8579(99)00032-1

[101] R. Fend, "Development of Medical Point-of-Care Applications for Renal Medicine and Tuberculosis Based on Electronic Nose Technology,” Ph.D. Thesis, Cranfield University, Silsoe, 2004.

[102] F. D. Francescoa, R. Fuocob, M. G. Trivellaa and A. Ceccarinib, "Breath Analysis: Trends in Techniques and Clinical Applications,” Microchemical Journal, Vol. 79, No. 1, 2005, pp. 405-410. doi:10.1016/j.microc.2004.10.008 